\title{
Congenital hereditary endothelial dystrophy associated with nail hypoplasia
}

\author{
R Stirling, J Pitts, N R Galloway, K Robson, R Newbury-Ecob
}

\begin{abstract}
Department of Ophthalmology, Nottingham R Stirling

J Pitts

N R Galloway
\end{abstract}

Department of Pathology, Nottingham K Robson

Department of Clinical Genetics, Nottingham R Newbury-Ecob

Correspondence to: Mr R Stirling, Department of Ophthalmology, University Hospital, Queens Medical Centre, Nottingham NG7 2UH.

Accepted for publication 17 August 1993

Figure 1 Left eye at 4 years of age showing diffuse corneal opacity.

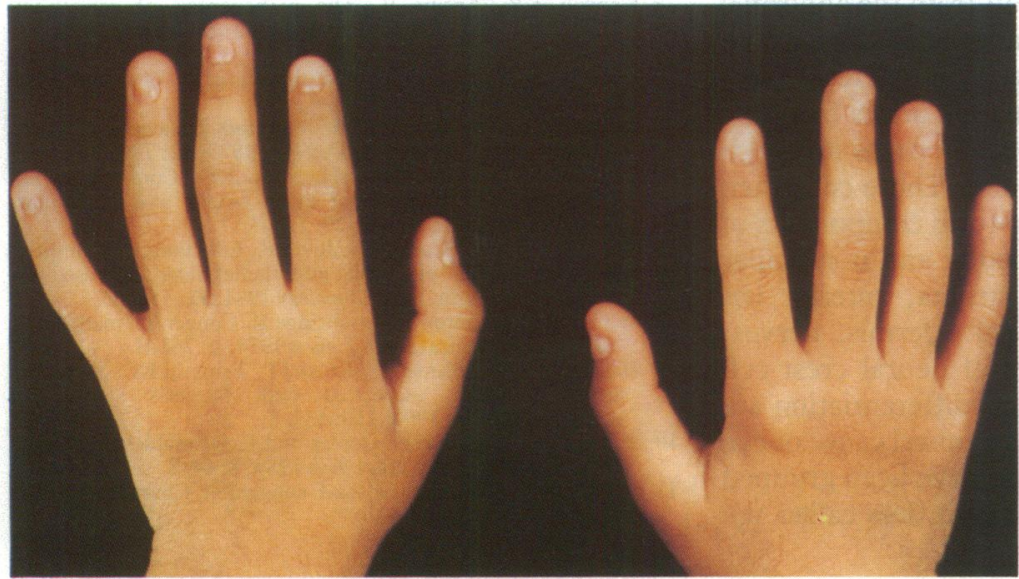

Figure 2 Nail hypoplasia affecting all digits of the hands.

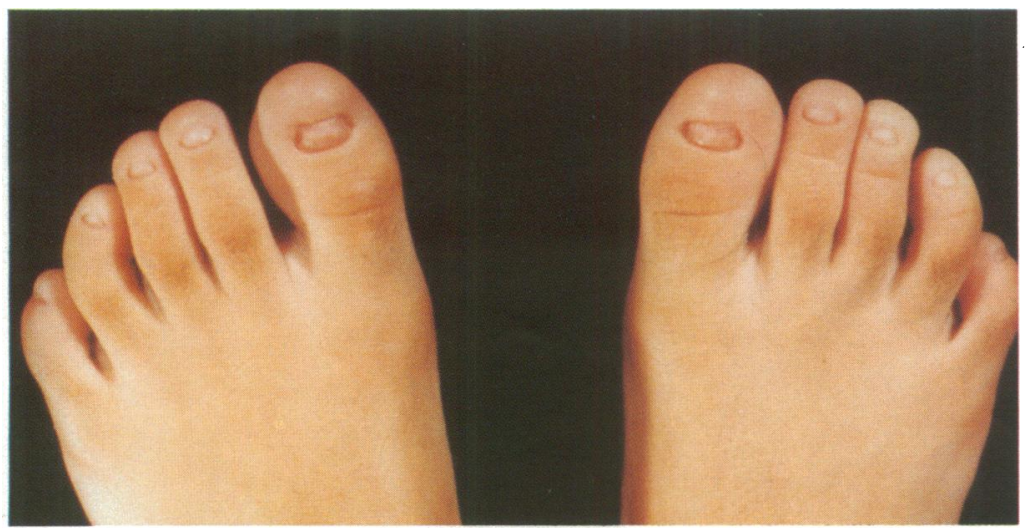

Figure 3 Nail hypoplasia affecting all digits of the feet. neural crest cells. The neurocristopathies display varied ocular and systemic abnormalities reflecting the widespread role of neural crest cells in embryogenesis. We describe a case of CHED associated with congenitally abnormal nails and postulate that both abnormalities can be explained by abnormal neural crest function.

\section{Case report}

A full term baby boy was born following an uneventful pregnancy by spontaneous vertex delivery. The birth weight was $2 \cdot 7 \mathrm{~kg}$. His parents were first cousins and of Pakistani origin. There was no history of maternal drug ingestion. Shortly after birth bilateral corneal opacities (Fig 1) and marked nail hypoplasia affecting all digits of the hands and feet (Figs 2 and 3) were noted. Mucopolysaccharidoses and cystinosis were excluded by biochemical screening and the lack of appropriate systemic features of these conditions. There was no serological or clinical evidence of maternal rubella during pregnancy and chromosomal analysis showed a normal $46 \mathrm{XY}$ karyotype. At 2 days of age an examination under ketamine anaesthesia was performed. This showed bilateral diffuse stromal corneal oedema but there were no other features suggestive of congenital glaucoma; corneal diameters were within the normal range for his age $(10 \mathrm{~mm}$ maximum horizontal diameter right and left), intraocular pressures measured by applanation tonometry were $14 \mathrm{~mm} \mathrm{Hg}$ right and $16 \mathrm{~mm} \mathrm{Hg}$ left; there were no Haab's striae, gonioscopy showed a normal open angle, and the optic discs were not cupped. An electroretinogram showed a normal response on both sides.

He was looking at and following faces shortly after birth and reaching for toys at 5 months. There was no strabismus or nystagmus. At the age of $\mathbf{3 0}$ months visual acuity was assessed at $6 / 60$ in each eye by Kay's pictures. At 4 years of age he underwent an uncomplicated right penetrating keratoplasty.

Light and transmission electron microscopy of the corneal button showed basal epithelial oedema (Fig 4), patchy disruption of Bowman's membrane, an unremarkable stroma, and thickening of Descemet's membrane to a maximum of $8.5 \mu \mathrm{m}$. The endothelial cells contained occasional vacuoles. The features were in keeping with a diagnosis of CHED.

Postoperatively there has been an improvement in visual acuity in the operated eye and to date the graft remains clear with a corrected visual acuity of $6 / 12$.

Both parents and all five siblings were also examined, none of whom showed any ocular or somatic abnormality. 


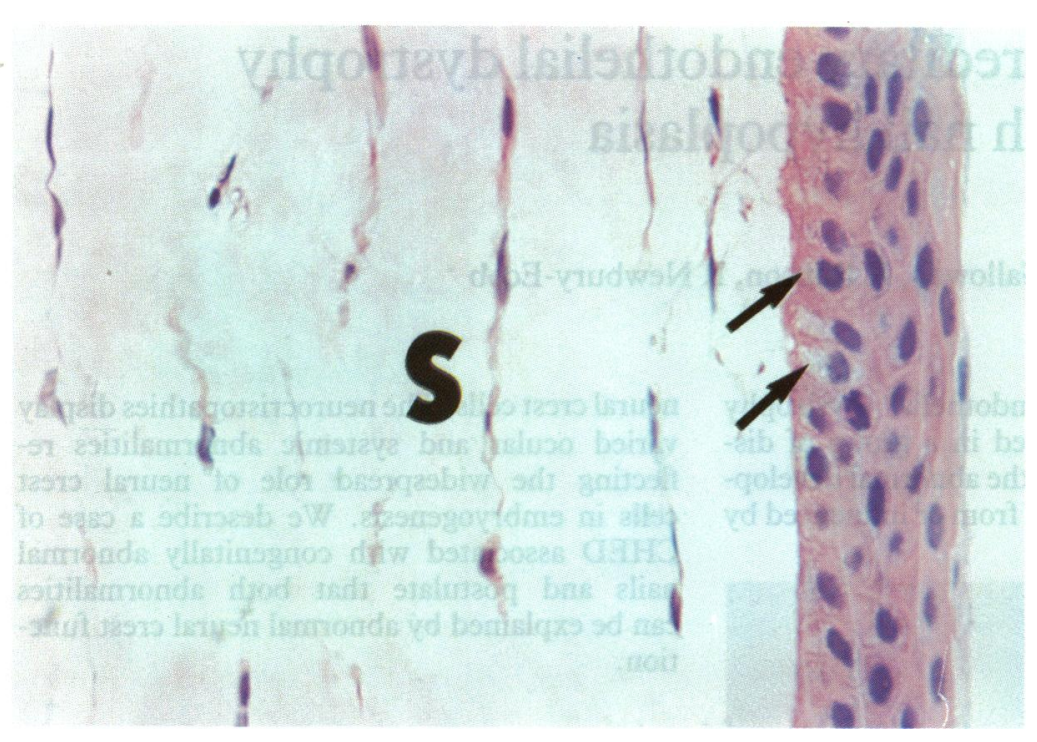

Figure 4 Light micrograph of the corneal button showing vaculated epithelial cells $(\lessdot)$ and stroma $(S)$. Haematoxylin and eosin, $\times 450$.

\section{Comment}

CHED presents early in life with bilateral diffuse corneal clouding and needs to be carefully differentiated from other causes of corneal opacity. ${ }^{1} \mathrm{~A}$ diagnosis of CHED was initially made by exclusion and was subsequently confirmed by light and electron microscopy of the corneal button.

As in our case, visual acuity is usually surprisingly well preserved given the degree of opacification. ${ }^{2}$ Inheritance of this condition may be either dominant or recessive, the latter being more common. Consanguinity and the lack of any ocular disease in the parents strongly suggest a recessive inheritance in this case.

CHED is thought to result from the abnormal differentiation of corneal endothelial cells, which are derived from primitive neural crest cells. ${ }^{3}$ The neural crest cell population arises from the lateral border of the neuroectoderm as it invaginates to form the neural tube. These cells then migrate and differentiate to form components of a heterogeneous array of ocular and non-ocular tissues including corneal stroma, anterior iris stroma, trabecular meshwork, dermis, nerves, and meninges. ${ }^{46}$ Disorders of neural crest cell migration, proliferation, and differentiation are now an increasingly well recognised cause of eye and other abnormalities, and have been grouped together to form a range of disorders called the neurocristopathies. Anterior segment abnormalities such as Axenfeld's, Rieger's, and Peter's anomalies, the iridocorneal endothelial syndromes, CHED, posterior polymorphous dystrophy, and Fuchs' endothelial dystrophy have all been included in this group. ${ }^{7}$

As well as being precursors of a wide range of cells themselves, neural crest cells may play a role in regulating the differentiation of other tissues. ${ }^{8}$ Rieger's anomaly, in particular, is associated with other somatic abnormalities including hypodontia, maxillary hypoplasia, hypertelorism, and distal limb abnormalities (Rieger's syndrome). ${ }^{9}$ Treacher Collins and Robert's syndromes in which there may be widespread ocular and non-ocular deformities have been classified as neurocristopathies. ${ }^{10}$ Thalidomide teratogenicity has also been included in this group. ." The limb deformities that are seen in this disorder are thought to be due to abnormal regulation of limb bud development by neural crest cells in utero. ${ }^{8}$ To our knowledge, however, no systemic abnormalities have previously been described in association with CHED.

We speculate that the abnormal nails in association with CHED in our patient represent a subtle form of abnormal regulation by neural crest cells and therefore provide further support for the inclusion of CHED as a neurocristopathy.

1 Maumenee AE. Congenital hereditary endothelial dystrophy. Am $\mathcal{F}$ Ophthalmol 1960; 60: 1114-24.

2 Kirkness CM, McCartney A, Rice NSC, Garner A, Steele AD. Congenital hereditary corneal oedema of Maumenee: its clinical features, management and pathology. Br $\mathcal{F}$ Ophthalmol 1987; 71: 130-44.

3 Kenyon KR, Antine B. The pathogenesis of congenital hereditary endothelial dystrophy of the cornea. Am $\mathcal{J}$ Ophthalmol 1971; 72: 787-95.

4 Weston JA. The migration and differentiation of neural crest cells. Adv Morph 1970; 8: 41-4.

5 Noden DM. An analysis of the migratory behaviour of avian cephalic neural crest cells. Dev Biol 1975; 42: 106-30.

6 Johnson MC, Noden DM, Hazleton RD, Coulombre JL, Coulombre AJ. Origins of avian ocular and periocular tissues. Exp Eye Res 1979; 29: 27-43.

7 Bahn CF, Falls H, Variey G, Mayer R, Edelhauser H, Bourne W. Classification of corneal endothelial disorders based on neural crest origin. Ophthalmology 1984; 91: 558-63.

8 McCredie J, Cameron J, Shoobridge R. Congenital malformations and the neural crest. Lancet 1978; ii: 761-3.

9 Steinsapir KD, Lehman E, Ernst JT, Tripathi RC. Systemic neurocristopathy associated with Rieger's syndrome. Am F Ophthalmol 1990; 110: 437-8.

10 Butler L, Willshaw HE. Ocular and facial maldevelopment: the role of the neural crest. Eye 1989; 3: 64-8.

11 McCredie J. Thalidomide and congenital Charcot's joints. 